\title{
Research on Key Issues of China's Project Water Price
}

\author{
Yanchen ZHOU ${ }^{\mathrm{a}, \mathrm{b}}$, Xiaoxia TONG ${ }^{\mathrm{a}, \mathrm{c}, 1}$, Zhengjie YIN ${ }^{\mathrm{a}, \mathrm{b}}$, Lisi XU ${ }^{\mathrm{a}, \mathrm{b}}$ \\ ${ }^{a}$ Yangtze River Scientific Research Institute of Changjiang Water Resources Commission, \\ 430010, Wuhan, China \\ ${ }^{b}$ Key Laboratory of Water Resources and Eco-Environmental Science of Hubei Province, \\ 430010, Wuhan, China \\ ${ }^{c}$ Key Laboratory of Water Resources and Hydropower Engineering Science, Wuhan \\ University, Wuhan 430072, China
}

\begin{abstract}
Focusing on China's current water price issues, such as "difficulty in pricing, adjustment, charging, and effectiveness" and the others, the current water conservancy project water supply system has been sorted out in terms of water price formation mechanism, water price composition, influencing factors, price system structure, and pricing technology. Quantitative analysis has been carried out on the problems with prices. At the same time, based on the experience and lessons of similar policies and system reforms at home and abroad, the study puts forward the long-term mechanism of water fee collection and subsidy and the implementation of safeguard measures and recommendations for the water supply price system of water conservancy projects.
\end{abstract}

Keywords. Project water price, pricing mechanism, experience for reference, water price elasticity, affordability

\section{Research Background}

The shortage of water resources in our country and the inherent deficiencies of uneven temporal and spatial distribution, coupled with equal emphasis on waste and pollution, have led to the formation of various water shortages such as management, engineering, and water quality. In recent years, the impact of extreme climate change has increased, which has increased the risk and uncertainty of my country's water resources. Together with food and oil, water resources have become an important strategic resource for sustainable economic and social development. The contradiction between water supply and demand has become a major bottleneck restricting my country's sustainable development. In 2014, the central government put forward the water control policy of "two-handed effort" by the government and the market to ensure water security. The use of market means to adjust the contradiction between water supply and demand, promote the conservation and optimal allocation of water resources, has become a new era of water resources in my country. The key tasks of scientific and efficient management. However,

\footnotetext{
${ }^{1}$ Corresponding Author: Xiaoxia Tong, Yangtze River Scientific Research Institute of Changjiang Water Resources Commission, 430010,Wuhan, China; E-mail: ckytxx@163.com

This work is funded by the National Key R\&D Program (2017YFC0404504), the National Natural Science Foundation of China (No. 51809009), Key Research Project of Ministry of Water Resources (CKSK2020327/SZ); Special thanks are given to the anonymous reviewers and editors for their constructive comments.
} 
water prices in my country have been low for a long time and cannot effectively reflect changes in water supply costs such as supply-demand relations and price changes[1]. The price elasticity of water supply and demand is lacking, and the role of the market in regulating water supply and demand has not been effectively brought into play. In the past decade, many water supply units and enterprises have generally fallen into a dilemma of "low price and low quality"[2]. Affected by government pricing, public welfare water supply awareness, unscientific cost accounting, water resource fees and sewage treatment fees adjustments, etc., price adjustments are difficult to coexist with improper operation. The responsibilities of the government and enterprises are unclear, and the sharing mechanism is unscientific. The problems are prominent and policy-oriented. Losses and operating losses occur from time to time.

Water supply behavior has a public welfare attribute. The government sets prices low in order to protect the people's livelihood. At the same time, water price adjustment cycles are long and restrictive. In terms of water supply companies, there are problems such as poor management and operation, long-term losses, and insufficient maintenance of the water supply pipe network. The safety of water supply is threatened, and the long-term interests of both the supply and demand sides have been threatened for a long time. At present, China's water supply price does not fully play the role of the two-way market regulation of supply and demand, and there is an imbalance and asymmetry in water supply costs and prices. The boundary between government and market responsibilities is not clear, and the management of urban water supply costs and prices fails, and it is difficult to give full play to the corresponding incentives and restraints.

In order to do a good job in the research on the major issues of price work in the new era and the new normal, take international experience as reference[3-7], clarify the current water supply costs in the water supply industry of water conservancy projects and the implementation of water supply prices and other management problems and causes, seek further measures and methods to solve the problems, and clarify water prices The direction and goal of the reform have become an important way and inevitable situation to realize the rational and efficient allocation of water resources and alleviate the contradiction between water supply and demand.

\section{Project Water Price}

\subsection{Water Price Formation Mechanism}

With the goal of ensuring water fairness, promoting the rational allocation of water resources and sustainable development, and taking into full consideration the basis of water price determination and comprehensive influencing factors, government departments, water supply and sewage treatment related departments, and water users follow certain guidelines and procedures to This kind of collaborative relationship jointly sets and regulates the work content and process of water supply prices, including cost estimation, organizational system, supervision and inspection, review and approval, implementation and implementation, and related system and policy arrangements. Pricing bodies: water resources prices are determined by the government, industrial and commercial water markets are determined, urban residents' domestic water government markets are jointly determined, and agricultural production and rural water supply governments are determined[8]. 
The scientific water price formation mechanism must reflect the multiple values of water commodities, the shortage of water resources, the supply and demand of water, and the influence of various factors such as economic and social factors, implement scientific water price pricing methods, and form a scientific relationship between price comparison and price difference. Different water price structures are formed according to different water quantity, water quality, purpose, region, season, peak and valley, and even different water supply projects. A reasonable water price has two meanings: First, its cost should be composed of resource costs, engineering (storage and transportation) costs, water production costs, environmental costs, plus reasonable profits and taxes to form a complete cost that is suitable for sustainable development. Water price; Second, the supply and demand of water resources determined by water price cannot exceed the carrying capacity of water resources and the carrying capacity of water environment. The level of revenue and expenditure determined by water price must ensure the continuous operation of water supply projects and the ability of water users to pay. In other words, the sustainable development of water prices must be able to ensure the sustainable development and utilization of water resources, so that the environment and foundation of water resources regeneration and recycling are not damaged, while taking into account the affordability of water supply projects and the affordability of water users.

\subsection{Water Price Composition}

Water resources have the multiple functions and value characteristics of general natural resources. They are scarce resources. The development and utilization of water resources for economic and social water supply activities not only involve ecological environmental protection and the sustainable use requirements of intergenerational inheritance, but also related to the current economic and social development. The economic benefits, utilization efficiency and consumer rights of the country also produce negative external effects after water and drainage. Therefore, the price of water supply for water conservancy projects should reflect all aspects involved in the development and utilization of water resources. From the analysis of the industrial chain of water supply price formation of water conservancy projects, the water supply of water conservancy projects includes three links: production, operation, and consumption. The formation of terminal prices is the transmission and superposition of costs, prices, and values in each link.

From the perspective of sustainable development, as well as drawing on the successful international experience in the development and utilization of natural resources and the regulation of natural monopoly industries, the price of water supply for water conservancy projects generally adopts full-cost pricing $[9,10]$. The full-cost water supply price consists of resource costs, engineering costs, environmental costs, taxes and profits. Among them, (1) The cost of resources reflects the ownership of the country, reflects the state as a representative of water resources owned by the whole people to safeguard the rights and interests of common property and social welfare, and reflects the scarcity and water quality differential taxation. This is the economic form of the transfer of all the country's water resources; (2) Project cost is the input cost for turning resource water into product water and making it into the market into commercial water, including engineering fees (reconnaissance, design and construction, etc.), service fees (including operation, operation, management, Maintenance and repairs, etc.) and capital costs (interest and depreciation, etc.). This part of the cost is the most direct cost that constitutes the price of water supply, that is, it is composed of three parts commonly known as raw water cost, 
water production cost and water supply operation cost; (3) Environmental cost refers to the manifestation of external costs caused by water resources development and utilization activities, that is, the economic compensation price that causes the reduction of ecological environment functions; (4) Taxes refer to water supply operators that should be paid in accordance with the national tax law and can be included in the water price. Tax; (5) Profit refers to the reasonable income obtained by the water supply operator from engaging in normal water supply production and operation, which is determined by the profit rate of net assets.

Full-cost water supply price $=$ water resource tax + raw water fee (water production cost $)+$ water supply operation cost + sewage treatment fee + business tax + profit

\subsection{Water Price Pricing Method}

Principles: fairness, reasonable distribution and compensation of benefits, dynamic adjustment, promoting the efficient allocation of water resources, reasonable sharing.

The water supply of water conservancy projects has a strong public welfare and a certain degree of profitability. For the business affairs of water production and water supply invested by non-specific assets, the government should gradually transfer specific service functions such as water production and water supply to the main body of the enterprise, and withdraw from urban water supply Specific operations and services in the industry. The cost and benefits of water supply can be shared according to the principle of "who is responsible for funding, who benefits and who invests". The forms of government sharing mainly include infrastructure investment, financial subsidies, and tax incentives. Financial subsidies are one of the main ways. When determining a reasonable amount of financial subsidies, it is necessary to pass cost supervision and review, determine the average production cost of the water supply industry, and define the nature of the company's loss: policy loss or operating loss. Generally, only policy losses are subsidized, and operating losses are not subsidized. Policy-related loss subsidies can consider a combination of direct fiscal subsidies and cross subsidies (implementing tiered water prices to realize the use of riches to make up for the poor).

\section{Current Water Price}

\subsection{Water Fee Collection}

Regarding water fees for water conservancy projects, the national water fee collection rate for large, medium and small water conservancy projects (including some projects directly under the central government and projects in various provinces and cities under separate plans) is about $72 \%$, of which the lowest is $17 \%$ in Beijing, and Jiangxi, Sichuan, Hunan, Dalian and directly under the central government. For the project (part of the sample), the water fee collection rate is less than 50\%. Guangdong, Jiangsu, Ningxia, Shaanxi, Xiamen, Liaoning, Ningbo, Qingdao and other provinces (autonomous regions, cities) have higher water fee collection rates than $90 \%$. Water charges in various provinces are given in Table 1 . 
Table 1. Collection of water charges in various provinces

\begin{tabular}{|c|c|c|c|c|c|c|c|c|}
\hline \multirow{2}{*}{ Province } & \multicolumn{3}{|c|}{ Irrigated area } & \multicolumn{3}{|c|}{ Reservoir } & \multicolumn{2}{|c|}{ Rural drinking water } \\
\hline & Scale & Number & Rate & Scale & Number & Rate & Number & Rate \\
\hline \multirow{3}{*}{ Central } & 1 & 1 & & Large & 4 & & & \\
\hline & 1 & 1 & 1 & Small & 0 & $46 \%$ & 1 & 1 \\
\hline & 1 & 1 & & Medium & 1 & & & \\
\hline \multirow{3}{*}{ Beijing } & 1 & 1 & & Large & 3 & & & \\
\hline & 1 & 1 & 1 & Small & 9 & $17 \%$ & 91 & $72.30 \%$ \\
\hline & 1 & 1 & & Medium & 10 & & & \\
\hline \multirow{3}{*}{ Tianjin } & 1 & 1 & & Large & 0 & & & \\
\hline & 1 & 1 & 1 & Small & 1 & 1 & 1 & 1 \\
\hline & 1 & 1 & & Medium & 7 & & & \\
\hline \multirow{3}{*}{ Hebei } & Large & 7 & & Large & 11 & & & \\
\hline & Small & 4 & $49 \%$ & Small & 0 & $75 \%$ & 2550 & $92.10 \%$ \\
\hline & Medium & 10 & & Medium & 11 & & & \\
\hline \multirow{3}{*}{ Shanxi } & Large & 10 & & Large & 7 & & & \\
\hline & Small & 14 & $83 \%$ & Small & 28 & $78 \%$ & 4027 & $78.70 \%$ \\
\hline & Medium & 132 & & Medium & 61 & & & \\
\hline \multirow{3}{*}{ Mongolia } & Large & 5 & & Large & 4 & & & \\
\hline & Small & 10 & $79 \%$ & Small & 15 & $63 \%$ & 235 & $88.20 \%$ \\
\hline & Medium & 17 & & Medium & 28 & & & \\
\hline \multirow{3}{*}{ Liaoning } & Large & 3 & & Large & 2 & & & \\
\hline & Small & 2 & $49 \%$ & Small & 0 & $63 \%$ & 1017 & $80.10 \%$ \\
\hline & Medium & 12 & & Medium & 15 & & & \\
\hline \multirow{3}{*}{ Jilin } & Large & 14 & & Large & 4 & & & \\
\hline & Small & 7 & $70 \%$ & Small & 3 & $69 \%$ & 3234 & $89.50 \%$ \\
\hline & Medium & 89 & & Medium & 28 & & & \\
\hline \multirow{3}{*}{ Heilongjiang } & Large & 14 & & Large & 1 & & & \\
\hline & Small & 2 & $71 \%$ & Small & 1 & $56 \%$ & 1697 & $91.80 \%$ \\
\hline & Medium & 10 & & Medium & 5 & & & \\
\hline \multirow{3}{*}{ Jiangsu } & Large & 6 & & Large & 7 & & & \\
\hline & Small & 0 & $90 \%$ & Small & 15 & $93 \%$ & 43 & $90.70 \%$ \\
\hline & Medium & 3 & & Medium & 34 & & & \\
\hline \multirow{3}{*}{ Zhejiang } & Large & 0 & & Large & 14 & & & \\
\hline & Small & 0 & $0 \%$ & Small & 12 & $76 \%$ & 1727 & $98.40 \%$ \\
\hline & Medium & 0 & & Medium & 82 & & & \\
\hline \multirow{3}{*}{ Anhui } & Large & 13 & & Large & 11 & & & \\
\hline & Small & 33 & $56 \%$ & Small & 20 & $86 \%$ & 2116 & $85.20 \%$ \\
\hline & Medium & 71 & & Medium & 81 & & & \\
\hline
\end{tabular}




\begin{tabular}{|c|c|c|c|c|c|c|c|c|}
\hline \multirow{2}{*}{ Province } & \multicolumn{3}{|c|}{ Irrigated area } & \multicolumn{3}{|c|}{ Reservoir } & \multicolumn{2}{|c|}{ Rural drinking water } \\
\hline & Scale & Number & Rate & Scale & Number & Rate & Number & Rate \\
\hline & Large & 4 & & Large & 8 & & & \\
\hline \multirow[t]{3}{*}{ Fujian } & Small & 35 & $35 \%$ & Small & 43 & $68 \%$ & 2349 & $93.30 \%$ \\
\hline & Medium & 215 & & Medium & 72 & & & \\
\hline & Large & 10 & & Large & 2 & & & \\
\hline \multirow[t]{3}{*}{ Jiangxi } & Small & 22 & $49 \%$ & Small & 7 & $28 \%$ & 1049 & $93.50 \%$ \\
\hline & Medium & 82 & & Medium & 35 & & & \\
\hline & Large & 13 & & Large & 4 & & & \\
\hline \multirow[t]{3}{*}{ Shandong } & Small & 0 & $67 \%$ & Small & 6 & $63 \%$ & 3331 & $90.00 \%$ \\
\hline & Medium & 1 & & Medium & 10 & & & \\
\hline & Large & 35 & & Large & 23 & & & \\
\hline \multirow[t]{3}{*}{ Henan } & Small & 28 & $39 \%$ & Small & 127 & $69 \%$ & 2991 & $87.60 \%$ \\
\hline & Medium & 80 & & Medium & 120 & & & \\
\hline & Large & 22 & & Large & 23 & & & \\
\hline \multirow[t]{3}{*}{ Hubei } & Small & 2 & $67 \%$ & Small & 8 & $76 \%$ & 2755 & $89.40 \%$ \\
\hline & Medium & 36 & & Medium & 59 & & & \\
\hline & Large & 0 & & Large & 6 & & & \\
\hline \multirow[t]{3}{*}{ Hunan } & Small & 0 & $0 \%$ & Small & 15 & $34 \%$ & 3295 & $30.90 \%$ \\
\hline & Medium & 0 & & Medium & 137 & & & \\
\hline & Large & 2 & & Large & 8 & & & \\
\hline \multirow[t]{3}{*}{ Guangdong } & Small & 10 & $32 \%$ & Small & 17 & $91 \%$ & 615 & $92.60 \%$ \\
\hline & Medium & 174 & & Medium & 221 & & & \\
\hline & Large & 5 & & Large & 10 & & & \\
\hline \multirow[t]{3}{*}{ Guangxi } & Small & 25 & $36 \%$ & Small & 36 & $75 \%$ & 105 & $89.40 \%$ \\
\hline & Medium & 79 & & Medium & 37 & & & \\
\hline & Large & 0 & & Large & 0 & & & \\
\hline \multirow[t]{3}{*}{ Chongqing } & Small & 1 & $26 \%$ & Small & 37 & $83 \%$ & 128 & $90.40 \%$ \\
\hline & Medium & 5 & & Medium & 44 & & & \\
\hline & Large & 14 & & Large & 0 & & & \\
\hline \multirow[t]{3}{*}{ Sichuan } & Small & 26 & $35 \%$ & Small & 44 & $34 \%$ & 738 & $93.20 \%$ \\
\hline & Medium & 117 & & Medium & 53 & & & \\
\hline & Large & 13 & & Large & 7 & & & \\
\hline \multirow[t]{3}{*}{ Yunnan } & Small & 43 & $51 \%$ & Small & 34 & $70 \%$ & 4121 & $75.30 \%$ \\
\hline & Medium & 163 & & Medium & 176 & & & \\
\hline & Large & 9 & & Large & 2 & & & \\
\hline \multirow[t]{2}{*}{ Shanxi } & Small & 4 & $90 \%$ & Small & 6 & $97 \%$ & 2761 & $83.20 \%$ \\
\hline & Medium & 38 & & Medium & 9 & & & \\
\hline Gansu & Large & 29 & $82 \%$ & Large & 2 & $82 \%$ & 2132 & $89.40 \%$ \\
\hline
\end{tabular}




\begin{tabular}{|c|c|c|c|c|c|c|c|c|}
\hline \multirow{2}{*}{ Province } & \multicolumn{3}{|c|}{ Irrigated area } & \multicolumn{3}{|c|}{ Reservoir } & \multicolumn{2}{|c|}{ Rural drinking water } \\
\hline & Scale & Number & Rate & Scale & Number & Rate & Number & Rate \\
\hline & Small & 31 & & Small & 13 & & & \\
\hline & Medium & 234 & & Medium & 17 & & & \\
\hline & Large & 0 & & Large & 2 & & & \\
\hline \multirow[t]{3}{*}{ Qinghai } & Small & 2 & \multirow{3}{*}{$77 \%$} & Small & 13 & $69 \%$ & 4354 & $65.40 \%$ \\
\hline & Medium & 10 & & Medium & 3 & & & \\
\hline & Large & 11 & & Large & 0 & & & \\
\hline \multirow[t]{3}{*}{ Ningxia } & Small & 42 & $86 \%$ & Small & 33 & $96 \%$ & 46 & $90.10 \%$ \\
\hline & Medium & 28 & & Medium & 26 & & & \\
\hline & Large & 53 & & Large & 1 & & & \\
\hline \multirow[t]{2}{*}{ Xinjiang } & Small & 11 & $90 \%$ & Small & 2 & $83 \%$ & 308 & $90.80 \%$ \\
\hline & Medium & 32 & & Medium & 9 & & & \\
\hline
\end{tabular}

\subsection{Cost Recovery}

Cost recovery of agricultural water supply projects. In large-scale irrigation districts, $33.21 \%$ of the national water charges can be guaranteed for operating costs, and projects that can guarantee operating costs plus depreciation account for only $22.4 \%$ of the total. Inner Mongolia, Guangxi, Yunnan, Gansu, Xinjiang and other provinces have a relatively high proportion; medium-sized irrigation areas, The proportion of guaranteed operating costs in the country accounts for $26.38 \%$, and the projects that can guarantee operating costs plus depreciation account for only $22 \%$ of the total. Provinces and regions such as Qinghai, Heilongjiang, Hubei, and Xinjiang account for more than $50 \%$ of the operating costs; small-scale irrigation areas, The proportion of guaranteed operating expenses nationwide is $20.69 \%$, the proportion of projects that guarantee operating expenses plus depreciation is $20.3 \%$, and the proportion of guaranteed operating expenses in Heilongjiang, Hubei, Gansu, Shanxi, Shaanxi and other provinces is more than 50\%; in general, the project The smaller, the lower the proportion of projects that guarantee operating costs, and the performance of the Northwest region is slightly better than other regions.

Cost recovery of non-agricultural water supply projects. For large-scale reservoir projects, the proportion of the nation's guaranteed operating costs accounted for $27.40 \%$, and the projects that can guarantee operating costs and depreciation accounted for only $12.33 \%$ of the total. Yunnan, Zhejiang, Shaanxi and other provinces have a higher proportion. For medium-sized reservoir projects, $36.86 \%$ of the country can guarantee operating costs, while projects that can guarantee operating costs and depreciation account for only $31.57 \%$ of the total. Provinces such as Shandong, Zhejiang and Anhui have a higher proportion. For small reservoir projects, $26.59 \%$ of the country can guarantee operating costs, and projects that can guarantee operating costs and depreciation account for only $21.97 \%$ of the total. The proportion of operating expenses in Fujian, Chongqing and other provinces is more than $50 \%$.

Cost recovery of rural water supply projects. For rural drinking water safety water supply projects, according to the survey of the implementation of tax preferential policies for the construction and operation of rural drinking water safety projects, a statistical analysis of 47,866 rural drinking water safety projects nationwide. Among them, the water 
supply price in Sichuan, Beijing, Jiangsu and other regions is greater than the water supply cost, and the water supply price in Ningxia, Xinjiang, Shandong, Inner Mongolia and other regions is less than the water supply cost. Supply cost and water supply price of rural drinking water is shown in Table 2 .

Table 2. Supply cost and water supply price of rural drinking water.

\begin{tabular}{ccc}
\hline Province & Water supply cost $\left(\right.$ Yuan $\left./ \mathbf{m}^{\mathbf{3}}\right)$ & Water price $\left(\right.$ Yuan $\left./ \mathbf{~ m}^{3}\right)$ \\
\hline Beijign & 2.99 & 3.67 \\
Shanxi & 2.11 & 2.24 \\
Mongolia & 4.5 & 2.5 \\
Liaoning & 3.54 & 2.51 \\
Jilin & 4.78 & 3.29 \\
Heilongjiang & 1.16 & 1.51 \\
Jiangsu & 1.78 & 2.27 \\
Zhejiang & 5.03 & 4.16 \\
Anhui & 1.79 & 1.89 \\
Fujian & 1.75 & 1.94 \\
Shandong & 3.59 & 1.97 \\
Henan & 2 & 1.8 \\
Hunan & 1.94 & 2 \\
Guangdong & 1.48 & 1.3 \\
Guangxi & 1.38 & 1.56 \\
Hainan & 1.67 & 1.67 \\
Chongqing & 3.01 & 1.98 \\
Sichuan & 2.58 & 3.32 \\
Guizhou & 1.94 & 2.19 \\
Yunnan & 1.94 & 1.56 \\
Shanxi & 2.57 & 2.41 \\
Gansu & 2.83 & 2.45 \\
Ningxia & 3.8 & 2.3 \\
Xinjiang & 3.21 & 1.66 \\
\hline
\end{tabular}

\subsection{Problem Analysis}

The water price level is low. All personnel of the water pipe unit divide the number of water supply personnel and the number of non-water supply personnel according to a certain ratio; the wages of water supply personnel are not calculated according to the actual wages, but are calculated according to a certain percentage of the average social wages, which are generally smaller than the actual wages; The maintenance cost is calculated according to the actual number of occurrences. The income of the water pipe unit is low, the government funding is insufficient, and the actual maintenance expenditure is much lower than the actual demand. 
It is difficult to adjust prices. When local governments adjust prices, they must consider the overall increase in local prices to meet the assessment goals of price control. Due to the characteristics of the public welfare nature of water supply, the government has a heavy psychological burden on price adjustments and the pressure of public opinion. The government would rather not adjust than bear the social risks caused by price adjustments. Water price adjustment does not form a linkage mechanism with related tax and fee adjustments. After any part of the various components of the terminal water price changes (water resource rates, sewage treatment fees, and profits and taxes, etc.), the entire process of cost supervision and review, hearings, and other price adjustments must be followed. The overall water price adjustment is obviously lagging behind other related tax and fee adjustments.

Pricing is difficult. In the survey of water supply costs, labor costs account for a high proportion, are they all included in water supply costs? Single project cost accounting formed a monopoly price, which did not reflect the average social cost. The cost supervision and examination system is not perfect.

It is difficult to collect. At present, China emphasizes poverty alleviation, exempts agricultural taxes and implements various subsidies, the collection of agricultural water prices is inconsistent with agricultural subsidy policies. Water management units, especially water management units that have been transformed into public welfare institutions, are not tied to income and lack the motivation to collect water fees. China's monitoring and measurement facilities are incomplete, and do not match the requirements of charging per party and charging to the household.

\section{International Water Price Experience}

\section{1. "How to Price"}

Developed countries generally require cost recovery in the pricing of water supply for water conservancy projects. Irrigation projects led by the federal and state in the United States require all construction and operation and maintenance costs to be recovered and related capital costs (interest) added, while enjoying interest subsidies and preferential treatment. Only part of the construction cost, operation and maintenance cost and capital cost (interest) of rural water supply projects are included in the pricing cost. Grants or special funds are not included in the cost; the United Kingdom implements full cost pricing for all water supply including agricultural water supply. France has subsidized agricultural water use; in India, government subsidies are more in water prices, and agricultural water supply only involves operation and maintenance costs. South Korea has not charged water fees for agricultural water supply in recent years. The above only involves engineering costs, corresponding to domestic resource costs and environmental costs. Pollution costs are generally included in the water price in developed countries, but the calculation of resource costs is not strict. Generally, water environment taxes are used, but it is not common.

\section{2. "How Much to Price"}

Due to differences in income levels and price levels in typical foreign countries, the overall level of water prices is different. When setting prices, it is generally necessary to consider 
the affordability of water users, but water prices, especially agricultural irrigation water prices, are also at a relatively low price, and the elasticity is not significant. Different crop types and irrigation technical conditions also lead to differences in the elasticity of agricultural water use. Among them, the elasticity of artesian irrigation water is relatively high. At present, the highest water prices are in the United States and Germany, with the highest being about US\$8 per cubic meter (including tap water and sewage treatment fees). Mexico's water bill burden rate (water bills as a proportion of household income) is up to $3.7 \%$, typical cities in developed countries are generally within $1 \%$, such as Washington at around $0.7 \%$, and the average household water bill in the UK is stable at $220-300$ pounds per year Within the range, only $0.3 \%$ of revenue.

\section{3. "How to Collect"}

In order to promote the collection of water charges, some countries have innovated charging methods. Both the supply and demand parties sign water contracts and pass laws to restrict water users to pay on time. For non-payment and delay in payment, financial sanctions were imposed, and methods such as stopping water supply were even adopted. Most areas in the United States implement a two-part water price, which is collected through a fixed service fee + a metered water fee. There are two charging methods in the $\mathrm{UK}$, one is metered, and the other is not metered, which is based on house size and level. The charges for water users who live in independent villas are higher and the charges for small houses are lower. In addition, certain concessions and exemptions are also given to families of students, families of unemployed workers, bankrupt families, and families with disabilities, including religious sites and charitable organizations. With the improvement of technical means, the implementation of pre-collected water charges began. The difficulty of payment management lies in the collection of agricultural water fees. In order to solve the problem of payment difficulties, countries mainly solve the problem by promoting the autonomy of water supply entities such as irrigation districts and strengthen payment management.

\section{Suggestion for Water Pricing}

At present, in my country's water conservancy and water supply projects, in addition to some of the original funds for project construction, most of the daily operation and maintenance funds of the projects come from water supply income, and the industry implements a self-financing management mechanism. Therefore, recovery of water supply operating costs and a slight profit are the business objectives of the water supply unit. Only by reflecting the cost of water supply and the profit target of the water supply unit, the water price can stimulate the enthusiasm of the water supply unit, improve the efficiency of water supply management, and increase the profitability of water supply.

China's agricultural water price reform and promotion area is still small, even less than $5 \%$ in some provinces and cities. It is necessary to tailor measures to local conditions and to formulate agricultural water price reform plans in accordance with the characteristics of local water resources and industrial structure characteristics, promote agricultural water price reform, and expand the area of agricultural water price reform and the area of agricultural water fee charging. 
General Secretary Xi Jinping's "3.14" speech deeply discussed the multiple attributes of water and its special status in the national economy and society, and determined that the government and the market must use both the government and the market to determine water prices. Further research clarified the basic concepts of water resource value, water price composition, and water price formation mechanism. In accordance with the instructions of Minister Hubei "Establishing a multi-level water supply price system according to the characteristics of different industries", researched and put forward preliminary ideas for the implementation of regional and water source pricing, and preliminary plans for "industrial profitability, meager living, agricultural irrigation, maintenance, and ecological subsidies". Pricing principles, through a reasonable price tax system and subsidy policies, gradually realize the role of water prices in regulating supply and demand, optimizing the allocation of water resources, and promoting water conservation.

\section{References}

[1] Li R, Tian DG. Get rid of the dilemma of agricultural water price and respond to the current situation. Reform. 2016; 09:107-114.

[2] Qin CH. Water Resource Pricing and Its Practice. China Institute of Water Resources and Hydropower Research, Beiing, 2013.

[3] Guo JJ, Chen S. International experience and enlightenment of water price formation mechanism. China Price. 2021; 3:90-93.

[4] Mayol A. Social and nonlinear tariffs on drinking water: Cui bono Empirical evidence from a natural experiment in France. Revue d'economie politique. 2018; 6: 1161-1185.

[5] Arbués F., Garcia-Valinas M. A., Martinez-Espiñeira R. Estimation of Residential Water Demand: a Stateof-the-Art Review. Journal of Socio-Economics. 2003; 1: 81-102.

[6] Grafton RQ, Ward MB, Hang T, Kompas T. Determinants of residential water consumption: Evidence and analysis from a 10-country household survey. Water Resources Research. 2011; 8:1-44.

[7] Mayol A, Saussier S. Contract renewals, prices and deprivatizations: The case of water in France. Applied Economics. 2021; 21: 2447-2456.

[8] Michael H, Andreas P. Do political links influence water prices? Determinants of water prices in Germany Utilities Policy.2021; 70: 101184.

[9] Ding JJ, Wu XB, Yu HP. Research on the Formation Mechanism of Agricultural Water Price Driven by Comprehensive Reform of Water Price-Taking Jingmen, Hubei Province as an Example China Rural Water and Hydropower, 2012; 3:119-122.

[10] Qin CH, Gan H, Jia L, et al. A model building for water price policy simulation and its application. Journal of Hydraulic Engineering. 2017; 45:109-116. 